Rev. Bras. Saúde Prod. Anim., Salvador, v.15, n.2, p.308-317 abr./jun., 2014 http://www.rbspa.ufba.br ISSN 15199940

\title{
Digestibilidade e tempo de retenção dos grãos de sorgo processados durante a ensilagem em equinos
}

\author{
Digestibility and retention time of grains of sorghum processed during ensilage in equine
OLIVEIRA, Kátia de ${ }^{1 *}$; BITTAR, Carla Maris Machado²; COSTA, Ciniro³; MEIRELLES, Paulo Roberto de Lima ${ }^{3}$; SOUTELLO, Ricardo Velludo Gomes de ${ }^{1}$

'Universidade Estadual Paulista, Curso de Zootecnia, Dracena, São Paulo, Brasil.

${ }^{2}$ Universidade de São Paulo, Escola Superior de Agricultura Luiz de Queiroz, Departamento de Zootecnia, Piracicaba, São Paulo, Brasil.

${ }^{3}$ Universidade Estadual Paulista, Faculdade de Medicina Veterinária e Zootecnia, Departamento de Melhoramento e Nutrição Animal, Botucatu, São Paulo, Brasil.

*Endereço para correspondência: katia@dracena.unesp.br.

\section{RESUMO}

Objetivou-se determinar em equinos a digestibilidade dos nutrientes e o tempo médio de retenção dos grãos de sorgo de baixo e alto teores de tanino submetidos na ensilagem a dois processamentos, prensagem e moagem. Foram utilizados quatro cavalos castrados sem raça definida delineados em blocos casualizados, resultando em quatro repetições por tratamento. Os tratamentos consistiram de silagens de grãos úmidos de sorgo de baixo tanino e alto teor de tanino submetidos a dois tipos de processamentos, prensagem e moagem, arranjados em esquema fatorial 2x2 (2 genótipos de sorgo e 2 processamentos na ensilagem). Observaram-se diferenças significativas entre as silagens com baixo e alto teor de tanino, bem como dos processamentos na ensilagem, no qual os melhores resultados obtidos foram para a silagem de grãos úmidos de sorgo de baixo tanino moída, com os valores para CDMS, CDMO, CDEB, CDPB e CDAmido, de 83,82; 83,91; 85,17; 86,56 e 84,72\%, respectivamente. Ainda, não se identificou efeito significativo entre os grãos estudados, bem como dos processamentos, sobre o tempo médio de retenção, com média de 17,5h. Concluiu-se que a moagem dos grãos de sorgo na ensilagem aumenta a digestibilidade dos nutrientes. O tempo médio de retenção em equinos apresentou-se similar entre os grãos de sorgo ensilados sob a forma prensada e moída.

Palavras-chave: cavalo, moagem, prensagem, saco de náilon móvel, tempo médio de retenção

\section{SUMMARY}

The objective was to evaluate apparent digestibility of nutrients and the mean retention time of high-moisture grains of sorghum with low (SLT) and high (SHT) tannin submitted to two processing during ensilage, grinding and rolling. There were used four castrated male horses, crossbred. It was used randomized block by design for four replications, totalizing four repetitions for each treatment. The treatments consisted of SLT e SHT submitted to two processing during ensilage, griding and rolling, in $2 \times 2$ factorial arrangement tested (2 sorghum genotypes and 2 processing). The daily DM intake was $2 \%$ body weight, this way the test-diets were composited by $30 \%$ SLT and $70 \%$ of hay. There observed differences $(\mathrm{P}<0.05)$ between SLT and SHT, as like, of processing method, in that best results were for grinding-SLT, whose means values were to DCDM, DCOM, DCCE, DCCP and DCStarch of 83.82, 83.91, 85.17, $86.56 \mathrm{e}$ $84.72 \%$. Furthermore, not identified significant effect between the grains studied, as well as the processing, on the mean retention time, with an average of $17.5 \mathrm{~h}$. It was concluded that the grinding of grain sorghum silage increases nutrient digestibility. The mean retention time in horses presented similar among grain sorghum silages as rolled and grinded.

Keywords: grinding, horse, mean retention time, mobile nylon bag, rolling 
Rev. Bras. Saúde Prod. Anim., Salvador, v.15, n.2, p.308-317 abr./jun., 2014 http://www.rbspa.ufba.br ISSN 15199940

\section{INTRODUÇÃO}

O grão de sorgo tem ganhado destaque nacionalmente, devido ao desenvolvimento de variedades com baixo teor de tanino, constituindo-se em cereal nutritivo para equinos (GOLLCHER et al., 2010). Os genótipos de alto tanino, por serem menos atacados por pássaros, têm sido produzidos (GARCIA et al., 2005; IGARASI et al., 2008a; ÍTAVO et al., 2009), disponibilizando no mercado brasileiro, grãos de sorgo de baixo e alto teores de tanino, para uso na alimentação animal (FIALHO et al., 2004).

A ensilagem de grãos é um recurso usado para se diminuir os custos com alimentação animal (ÍTAVO et al., 2006; SCAPINELLO et al., 2011), além de modificar fisicamente o amido, com o rompimento da matriz protéica, liberando grânulos de amido livres e corpos protéicos (ROONEY \& PFLUGFELDER, 1986; PATRÍ́CIO et al., 2006). Grãos de sorgo ensilados têm promovido a desativação dos taninos. Barcellos et al. (2006), relataram que este processamento diminui em $95 \%$ os teores de tanino presentes no sorgo. Tal constatação é benéfica, pois de acordo com Oliveira et al. (2007), a presença de do tanino na dieta de equinos, interfere negativamente sobre a digestibilidade da fibra, exercendo influência deletéria sobre a população microbiana no intestino grosso de cavalos.

O estudo do tempo médio de retenção da digesta é importante na avaliação nutricional dos alimentos, pois permite mensurar a extensão da digestão, podendo estar relacionado com melhor digestibilidade. Há pouca informação sobre a interação do tempo médio de retenção da digesta com a digestibilidade dos grãos de cereais, além de serem inconsistentes (GOBESSO et al., 2009). Assim, Julliand et al. (2006), relataram aumento na digestão do amido com o maior tempo de retenção, enquanto que Oliveira et al. (2007) não encontraram interferência do tempo sobre a digestibilidade.

Vários tipos de processamento têm sido estudados com a finalidade de se melhorar o valor nutricional dos grãos, sobretudo em relação ao amido (CASALECCHI et al., 2012). De acordo com Igarasi et al. (2008b), os grãos de sorgo necessitam ser mais intensamente processados para atingir digestibilidade ótima. Contudo, não há na literatura resultados sobre o efeito do processamento de grãos úmidos de sorgo ensilados sobre a digestibilidade em cavalos. Neste sentido, objetivou-se determinar em equinos a digestibilidade dos nutrientes e o tempo médio de retenção dos grãos úmidos de sorgo de baixo e alto teor de tanino submetidos na ensilagem a dois processamentos, prensagem e moagem.

\section{MATERIAL E MÉTODOS}

O experimento foi desenvolvido na Sala de Metabolismo de Equinos, pertencente ao Departamento de Zootecnia da Universidade Federal de Lavras. Quatro cavalos castrados sem raça definida (idade e peso corporal médios de seis anos e $330 \mathrm{~kg}$ ), foram utilizados em um delineamento em blocos casualizados, sendo a unidade experimental constituída por um animal, totalizando quatro repetições. Os tratamentos consistiram de silagens de grãos úmidos de sorgo de baixo tanino e alto tanino submetidos a dois tipos de processamentos, prensagem e moagem. Desta forma, os tratamentos foram arranjados em esquema fatorial $2 \times 2$ (dois genótipos de sorgo e dois processamentos). 
Rev. Bras. Saúde Prod. Anim., Salvador, v.15, n.2, p.308-317 abr./jun., 2014 http://www.rbspa.ufba.br ISSN 15199940

As variedades de sorgo (Sorghum bicolor L. Moench) utilizadas para a confecção das silagens de grãos úmidos foram Sara e BRS-701 para baixo e alto teores de tanino, respectivamente. A colheita dos mesmos foi efetuada na fase de maturação fisiológica, ocasião em que os grãos apresentaram 29,32 e $30,73 \%$ de U, para os genótipos de baixo e alto teores de tanino, respectivamente. Neste momento utilizou-se o equipamento destinado ao enchimento de silos tipo "bag" (BOELTER, modelo OB 20) para a moagem do material e alterando-se a regulagem deste equipamento, foi possível realizar a prensagem, que diminuiu a integridade dos grãos, ou seja, resultando na abertura dos mesmos. Devido à impossibilidade do uso de peneiras, pela umidade presentes nos grãos no momento da ensilagem, monitorou-se a granulometria deste material pela determinação do diâmetro geométrico médio de acordo com a metodologia descrita por Factori e al. (2008), obtendo-se valor de oito e doze milímetros para moagem e prensagem, respectivamente. Depois de processado, o material foi acondicionado em baldes de PVC $(20 \mathrm{~cm}$ de diâmetro com $40 \mathrm{~cm}$ de altura), com capacidade para aproximadamente $22 \mathrm{~kg}$, sendo devidamente vedado por um período de 45 dias. No momento da abertura dos silos foram feitas amostragens para análise da composição química da silagem.

A quantidade de alimento fornecida aos animais foi estabelecida, segundo as recomendações do National Research Council (NRC, 2007), visando atender às exigências nutricionais para a categoria. A ingestão diária de matéria seca (MS) foi de $2,0 \%$ do peso corporal, composta por $30 \%$ de silagem de grãos úmidos de sorgo de baixo tanino e $70 \%$ de feno de coast-cross, com fornecimento de sal mineral ad libitum (OLIVEIRA et al., 2012b). Desta forma, os cavalos ingeriram em média $2 \mathrm{~kg}$ de silagem de grãos úmidos de sorgo de baixo tanino e $4,6 \mathrm{~kg}$ de feno de coast-cross na MS. A dieta foi fornecida em três refeições diárias, às $8 \mathrm{~h} 00 ; 12 \mathrm{~h} 00 \mathrm{e} 17 \mathrm{~h} 00 \mathrm{e}$ as sobras foram retiradas e pesadas 15 minutos antes de cada refeição. As composições químicas do feno, das silagens de grãos úmidos de sorgo de baixo e alto tanino e da dieta experimental encontram-se na Tabela 1.

O experimento teve duração total de 20 dias, no qual os primeiros quinze dias corresponderam à fase de adaptação dos animais as instalações, dietas e condições de manejo, onde os animais ficaram alojados em baias individuais, medindo $2 \times 3 \mathrm{~m}$, com piso de cimento sem cama, com comedouro para ração e sal e bebedouro. Utilizou-se a técnica do saco de náilon móvel para determinar os coeficientes de digestibilidade aparente dos nutrientes. De acordo com Oliveira et al. (2012a), foram utilizados sacos de náilon de poliéster branco, de tamanho interno de $3,5 \times 6,5 \mathrm{~cm}$, com porosidade determinada de 60 micras. Dentro de cada saco de náilon foi colocado $1 \mathrm{~g}$ de amostra do alimento teste in natura (ANDRAE et al., 2003) mantendo-se a relação de 10 a $20 \mathrm{mg}$ de matéria seca de amostra por $\mathrm{cm}^{2}$ de superfície dos sacos, conforme recomendação de Nocek (1988).

A inserção dos sacos de náilon foi feita em quatro cavalos via sonda nasogástrica durante cinco dias consecutivos. Assim, às 13 horas do primeiro dia de passagem da sonda nasogástrica, foram inseridos por cavalo 13 sacos, sendo três repetições para cada alimento teste e mais um saco vazio, denominado branco. 
Rev. Bras. Saúde Prod. Anim., Salvador, v.15, n.2, p.308-317 abr./jun., 2014 http://www.rbspa.ufba.br ISSN 15199940

Tabela 1. Composição química dos alimentos e da dieta experimental ${ }^{1}$

\begin{tabular}{|c|c|c|c|c|c|c|c|}
\hline \multirow{2}{*}{ Alimento/Dieta } & \multirow{2}{*}{ MS (\%) } & \multicolumn{5}{|c|}{ Nutriente (\% MS) } & \multirow{2}{*}{$\begin{array}{c}\mathrm{EB} \\
\text { (Mcal/kg) }\end{array}$} \\
\hline & & MO & Amido & PB & FDN & FDA & \\
\hline Feno de coast-cross & 91,20 & 95,21 & 2,59 & 7,47 & 80,70 & 42,79 & 4,35 \\
\hline Sorgo ensilado baixo tanino & 70,68 & 98,57 & 62,94 & 12,91 & 16,64 & 3,97 & 4,51 \\
\hline Sorgo ensilado alto tanno & 69,27 & 98,22 & 61,82 & 11,44 & 19,85 & 9,47 & 4,43 \\
\hline $\begin{array}{l}\text { Feno } \\
\text { tanino }^{2}\end{array}+$ Sorgo ensilado baixo & 85,04 & 96,22 & 20,70 & 9,10 & 61,48 & 31,14 & 31,14 \\
\hline
\end{tabular}

${ }^{1}$ Dados calculados a partir da composição química dos alimentos; ${ }^{2}$ Dieta contendo $70 \%$ de feno de coast-cross e $30 \%$ de silagem de sorgo de baixo tanino.

$\mathrm{MS}=$ matéria seca; $\mathrm{MO}$ = matéria orgânica; $\mathrm{PB}$ = proteína bruta; FDN = fibra em detergente neutro;

$\mathrm{FDA}=$ fibra em detergente ácido; $\mathrm{EB}=$ energia bruta.

Cada animal, no final do período de coleta, totalizou um número de quinze repetições por alimento teste, para se obter resíduo adequado para as análises laboratoriais. A recuperação dos sacos de náilon nas fezes foi realizada quatro vezes ao dia, às $6 \mathrm{~h} 00 ; 12 \mathrm{~h} 00 ; 18 \mathrm{~h} 00 \mathrm{e} 24 \mathrm{~h} 00$, a partir do segundo dia de inserção dos sacos de náilon e foram imediatamente congelados para análises posteriores. Em momento apropriado os sacos de náilon foram descongelados em temperatura ambiente e em seguida lavados em água corrente até a água sair limpa (40 min) e levados à estufa com ventilação de ar forçada durante 72 horas a $60^{\circ} \mathrm{C}$. Os sacos que permaneceram no trato digestivo do cavalo por período superior a 96 horas foram desprezados, conforme Oliveira et al. (2012b). Ainda, os sacos de náilon recuperados, por tratamento, por animal, durante os dias de coleta foram abertos e os resíduos formaram uma amostra composta. Desta forma, os resíduos obtidos sofreram moagem em peneira com crivo de $1 \mathrm{~mm}$, identificados e utilizados nas análises bromatológicas. Antes do início do experimento, foi administrado vermífugo de amplo espectro aos cavalos.

O tempo médio de retenção (TMR) foi determinado algebricamente de acordo com Galyean (1993), adaptado para o uso do número de sacos de náilon recuperados nas fezes, a cada seis horas, por meio da equação:

$\mathrm{TMR}=\left(\Sigma \mathrm{B}_{\mathrm{i}} \times \mathrm{t}_{\mathrm{i}} \times \Delta \mathrm{t}_{\mathrm{i}}\right) / \Sigma \mathrm{B}_{\mathrm{i}} \times \Delta \mathrm{t}_{\mathrm{i}}$, em que, $\mathrm{B}_{\mathrm{i}}=$ número de sacos coletados ao tempo $=\mathrm{t}_{\mathrm{i}}$ e $\Delta \mathrm{t}_{\mathrm{i}}=$ intervalo de tempo entre as coletas atual e prévia.

As análises bromatológicas de MS, matéria orgânica $(\mathrm{MO})$, proteína bruta (PB), detergente neutro (FDN) e fibra em detergent ácido (FDA), dos alimentos e resíduos foram feitas segundo a metodologia descrita em Silva \& Queiroz (2006). Os valores de EB das silagens, feno e resíduos foram determinados de acordo com Silva \& Queiroz (2006), mediante uso de calorímetro adiabático (Parr Instruments $\mathrm{Co}$ ).

Os coeficientes de digestibilidade dos nutrientes e o tempo médio de retenção foram submetidos à análise de variância do SAS (STATISTICAL ANALYSIS SYSTEM, 2000). A comparação entre médias foi realizada pelo teste Tukey, a $5 \%$ de significância. 
Rev. Bras. Saúde Prod. Anim., Salvador, v.15, n.2, p.308-317 abr./jun., 2014 http://www.rbspa.ufba.br ISSN 15199940

\section{RESULTADOS E DISCUSSÃO}

Os coeficientes de digestibilidade (CD) dos nutrientes avaliados das silagens de sorgo demonstram que a silagem de grãos úmidos de sorgo baixo tanino possui melhor valor nutricional $(\mathrm{P}<0,05) \mathrm{em}$ relação a silagem de grãos úmidos de sorgo de alto tanino na alimentação de equinos (Tabela 2). Diferentemente ao publicado por Oliveira et al. (2007) para a mesma espécie animal e com suínos (PATRÍCIO et al., 2003), quando a ensilagem de grãos úmidos de sorgo de alto tanino, promoveu a desativação dos taninos, tornando-se semelhante ao grão de baixo tanino. Pesquisas avaliando o uso de grãos de sorgo secos de alto tanino relatam redução na digestibilidade da proteína e da energia, inibição da atividade microbiana e enzimática ao longo do trato digestivo para diversas espécies (CAMPOS et al., 2003; OLIVEIRA et al., 2013). Comportamento similar foi observado no atual ensaio, para a dieta contendo silagem de grãos úmidos de sorgo de alto tanino, sugerindo não ter havido benefício da ensilagem dos grãos de sorgo com alto teor de tanino na desativação do tanino, sobre os coeficientes de digestibiliade de nutrientes para cavalos em manutenção. Ainda, Cação et al. (2012) relataram que a ensilagem dos grãos silagem de grãos úmidos de de sorgo alto tanino não provocaram queda no teor de tanino, causando baixos valores de degradabilidade ruminal dos nutrientes em bovinos fistulados. Tal situação pode ter sido provocada pelo baixo teor de umidade das silagens de sorgo, pois na atual pesquisa o teor de umidade de $30,73 \%$ foi inferior aos ensaios citados acima, em que a ensilagem de grãos úmidos de sorgo promoveu desativação do tanino.

Tabela 2. Coeficientes de digestibilidade aparente em equinos da matéria seca (CDMS) e dos nutrientes dos grãos úmidos de sorgo com baixo (SBT) e alto (SAT) teores de tanino submetidos a moagem e prensagem na ensilagem (\% MS)

\begin{tabular}{|c|c|c|c|c|c|}
\hline \multirow{3}{*}{ Variável (\%) } & \multicolumn{4}{|c|}{ Tipo de processamento dos grãos } & \multirow{3}{*}{ CV $(\%)$} \\
\hline & \multicolumn{2}{|c|}{ Moagem } & \multicolumn{2}{|c|}{ Prensagem } & \\
\hline & SBT & SAT & SBT & SAT & \\
\hline CDMS & $83,82^{\mathrm{a}}$ & $67,91^{\mathrm{b}}$ & $29,13^{\mathrm{c}}$ & $18,55^{\mathrm{d}}$ & 4,36 \\
\hline CDMO & $83,91^{\mathrm{a}}$ & $67,99^{\mathrm{b}}$ & $30,30^{\mathrm{c}}$ & $19,95^{\mathrm{d}}$ & 4,46 \\
\hline CDEB & $85,17^{\mathrm{a}}$ & $70,05^{\mathrm{b}}$ & $38,17^{\mathrm{c}}$ & $29,29^{\mathrm{d}}$ & 3,38 \\
\hline CDPB & $86,56^{\mathrm{a}}$ & $73,00^{\mathrm{b}}$ & $49,78^{\mathrm{c}}$ & $47,19^{c}$ & 4,16 \\
\hline CDAmido & $84,72^{\mathrm{a}}$ & $73,96^{\mathrm{b}}$ & $22,24^{\mathrm{c}}$ & $13,53^{\mathrm{d}}$ & 4,98 \\
\hline
\end{tabular}

Médias com letras diferentes na mesma linha diferem $(\mathrm{P}<0,05)$ entre si pelo teste Tukey.

$\mathrm{CDMO}=$ coeficiente de digestibilidade da matéria orgânica; $\mathrm{CDEB}=$ coeficiente de digestibilidade da energia bruta; $\mathrm{CDPB}=$ coeficiente de digestibilidade da proteína bruta.

A digestibilidade da MS variou de $18,55 \%$ (silagem de grãos úmidos de sorgo de alto tanino prensada) a $83,82 \%$ (silagem de grãos úmidos de sorgo de baixo tanino moída), indicando efeito positivo do processamento físico sobre os grãos durante a ensilagem $(\mathrm{P}<0,05)$. A mesma tendência foi observada para $\mathrm{O}$ 
CDMO; CDPB; CDEB e CDAmido, sendo sempre superior os valores para as silagens de grãos úmidos de sorgo de baixo tanino moídas. De acordo com estas observações, diferenças têm sido notificadas entre moagem e prensagem, no qual o fornecimento de grãos de cereais moídos para equinos aumentou $(\mathrm{P}<0,05)$ a digestibilidade pré-cecal do amido (JULLIAND et al., 2006), não se observando este comportamento de resposta em relação a digestão total pelo trato digestório do amido. Similarmente, Bailoni et al. (2006) relataram significante melhora na digestibilidade de cavalos devido à prensagem da aveia em relação ao grão íntegro. Isto denota que a moagem realizada no atual ensaio melhorou a ação das enzimas digestivas, e assim, resultando em maior digestibilidade dos nutrientes pelos equinos, por aumentar a superfície de contato dos grãos com as secreções do trato digestório. Deve-se ressaltar que, a prensagem realizada nos grãos de sorgo úmidos durante a ensilagem, no presente estudo, resultou apenas em leve ruptura dos grãos de sorgo ensilados e associado ao pequeno tamanho dos grãos, que pode escapar a mastigação pelo cavalo, permite fazer a recomendação da moagem dos grãos de sorgo para serem ensilados, assegurando melhor aproveitamento dos nutrientes presentes no alimento para equinos.

A maioria das pesquisas que avaliam a digestão de amido de grãos de cereais na nutrição de cavalos encontra valores para o coeficiente de digestibilidade próximo de $100 \%$ (SANTOS et al., 2003; FOMBELLE et al., 2004; Al JASSIM, 2006; BAILONI et al., 2006; JULLIAND et al., 2006; OLIVEIRA et al. 2007, GOBESSO et al., 2008; GOBESSO \& ETCHICHURY, 2009), diferentemente ao atual ensaio, no qual o melhor resultado obtido foi de $84,72 \%$ grãos úmidos de sorgo de baixo tanino moídos na ensilagem. Esta resposta, provavelmente, deve-se ao fato da moagem e prensagem com diâmetro geométrico médio de 8 e $12 \mathrm{~mm}$, respectivamente, não ter promovido redução do tamanho de partícula de maneira semelhante ao ocorrido pela mastigação de grãos pelos cavalos. Ainda, Rooney \& Pflugfelder (1986), relatam que a região periférica do endosperma do grão de sorgo é extremamente densa, dura e resistente à penetração de água e à digestão, se tornando em barreira física à camada adjacente rica em amido. A análise conjunta destas observações sugere a necessidade de se utilizar granulometrias menores ao estudado para a predição da digestibilidade do amido em grãos de sorgo por meio da técnica do saco de náilon móvel para equinos (Tabela 3).

O valor médio do tempo médio de retenção das silagens de grãos úmidos de sorgo processadas foi de $17,5 \mathrm{~h}$, não identificando efeito do tipo de genótipo de sorgo ensilado bem como do processamento sobre o trânsito dos sacos de náilon em cavalos $(\mathrm{P}>0,05)$. Similarmente, Araújo et al. (2003), não verificaram efeito do processamento do grão de milho (graus de moagem de 1, 2 e $3 \mathrm{~mm}$ ) por meio da técnica do saco de náilon móvel, sobre o tempo de passagem dos sacos de náilon pelo tratogastrointestinal dos cavalos. Entretanto, Oliveira et al. (2007), verificaram tempo médio de retenção superior $(\mathrm{P}<0,05)$ de grãos de sorgo ensilado em relação ao mesmo seco, no qual o valor obtido foi de 40,08 e 37,9h, respectivamente, na alimentação de éguas. Esta consideração pode ter relevância, como justificativa à discrepância no tempo 
Rev. Bras. Saúde Prod. Anim., Salvador, v.15, n.2, p.308-317 abr./jun., 2014 http://www.rbspa.ufba.br ISSN 15199940

de retenção entre grãos ensilados e secos obtidos por meio da técnica do saco de náilon móvel. Assim, a observação de 17,5 h dos grãos ensilados (Tabela 3 ) em relação ao encontrado na literatura com grãos secos de 6,2 h (FOMBELLE et al., 2004) e de 1,6 à $9,9 \mathrm{~h}$, com média de $6,8 \mathrm{~h}$ na mesma espécie animal (JULLIAND et al., 2006), refletem as diferenças inerentes aos grãos ensilados, que possuem maior tempo de retenção no tratogastrointestinal de equinos em comparação aos grãos secos.

Tabela 3. Tempo médio de retenção (TMR) em equinos dos sacos de náilon contendo grãos úmidos de sorgo com baixo (SBT) e alto (SAT) teores de tanino submetidos a moagem e prensagem na ensilagem

\begin{tabular}{|c|c|c|c|c|c|}
\hline \multirow{3}{*}{ Variável } & \multicolumn{4}{|c|}{ Tipo de processamento dos grãos } & \multirow{3}{*}{$\mathrm{CV}(\%)$} \\
\hline & \multicolumn{2}{|c|}{ Moagem } & \multicolumn{2}{|c|}{ Prensagem } & \\
\hline & SBT & SAT & SBT & SAT & \\
\hline TMR (h) & 16,97 & 18,17 & 21,01 & 13,95 & 30,42 \\
\hline Média & \multicolumn{2}{|c|}{17,57} & \multicolumn{2}{|c|}{17,48} & 36,01 \\
\hline
\end{tabular}

Em relação ao processamento físico de grão durante a ensilagem, o atual ensaio atestou que a redução do tamanho de partícula originada da moagem aumenta o aproveitamento dos nutrientes pelos equinos. Contudo, pequena informação encontra-se disponível sobre a interação do tempo de retenção da digesta com a digestibilidade do amido de grãos de cereais, além de serem inconsistentes. Vale salientar que, a melhora na digestão dos nutrientes dos grãos de sorgo úmidos de baixo tanino moídos durante a ensilagem (Tabela 2) foi devida a maior exposição do conteúdo dos grãos à ação de enzimas digestivas e pela degradação microbiana ocorrida no tratogastrointestinal, como conseqüência do processamento físico na ensilagem, não havendo interferência do tempo médio de retenção sobre os resultados. Desta forma pode-se concluir que a moagem dos grãos de sorgo na ensilagem aumenta a digestibilidade dos nutrientes. Ainda, o tempo médio de retenção em equinos apresentou-se similar entre os grãos de sorgo ensilados sob a forma prensada e moída.

\section{REFERÊNCIAS}

Al JASSIM, R.A.M. Supplementary feeding of horses with processed sorghum grains and oats. Animal Feed Science Technology, v.125, p.33-44, 2006.

ANDRAE, J.G.; HUNT, C.W.; PRITCHARD, G.T. Effect of hybrid, maturity, and mechanical processing of corn silage on intake and digestibility by beef cattle. Journal of Animal Science, v.79, p.2268-2275, 2003.

ARAÚJO, K.V.; LIMA, J.A.F.; FIALHO, E.T. Comparação da técnica do saco de náilon móvel com o método de coleta total para determinar a digestibilidade dos 
Rev. Bras. Saúde Prod. Anim., Salvador, v.15, n.2, p.308-317 abr./jun., 2014 http://www.rbspa.ufba.br ISSN 15199940

nutrientes de alimentos concentrados em equinos. Ciência Agrotécnica, v.25, n.2, p.375-384, 2003.

BAILONI, L.; MANTOVANI, R.; PAGNIN, G. Effects of physical treatments on the resistant starch content and in vitro organic matter digestibility of different cereals in horses. Livestock Science, v.100, p.14-17, 2006.

BARCELLOS, L.C.G.; FURLAN, A.C.; MURAKAMI, A.E.; SILVA, M.A.A.; SILVA, R.M. Avaliação nutricional da silagem de grãos úmidos de sorgo de alto e baixo conteúdo de tanino para frangos de corte. Revista Brasileira de Zootecnia, v.35, n.1, p.104-112, 2006.

CAÇÃO, M.M.F.; COSTA, C.; MEIRELLES, P.R.L. Degradabilidade ruminal da matéria seca de grãos de milho e de sorgo com alto ou baixo conteúdo tanino processados. Revista Brasileira de Saúde e Produção Animal [online], v.1, n.2, p.516-528, 2012.

CAMPOS, W.E.; SATURNINO, H.M.; SOUSA, B.M. Degradabilidade in situ da silagem de quatro genótipos de sorgo com e sem tanino: II - Fibra detergente neutro, fibra detergente ácido, hemicelulose e celulose. Arquivo Brasileiro de Medicina Veterinária e Zootecnia, v.55, n.4, p.450-453, 2003.

CASALECCHI, F.L.; ETCHICHURY, M.; GONZAGA, I.V.F.; GOBESSO, A.A.O. Digestibilidade aparente total e resposta glicêmica de dietas para eqüinos contendo milho submetido a diferentes processamentos. Brazilian Journal of Veterinary Research and Animal Science, v.49, n.3, p.232-238, 2012.
FACTORI, M.A.; COSTA, C.; MEIRELLES, P.R.L.; OLIVEIRA, K.; ROSALES, L.A.; MORAES, G.J.; GONÇALVES, H.C. Degradabilidade ruminal de híbridos de milho em função do estádio de colheita e processamento na ensilagem. Boletim de Indústria Animal, v.65, n.3, p.259-273, 2008.

FIALHO, E.T.; LIMA, J.A.F.; VLADIMIR, O.; SILVA, H.O. Substituição do milho pelo sorgo sem tanino em rações de leitões: digestibilidade dos nutrientes e desempenho animal. Revista Brasileira de Milho e Sorgo, v.1, n.1, p.105-111, 2004.

FOMBELLE, A.; VEIGA, L.; DROGOUL, C. Effect on diet composition and feeding pattern on prececel digestibility of starches from diverse botanical origins measured with the mobile nylon bag technique in horses. Journal of Animal Science, v.82, p.3625-3634, 2004.

GALYEAN, M.L. Technical note: an algebric method for calculating fecal output from a pulse dose of an external marker. Journal of Animal Science, v.71, p.3466-3469, 1993.

GARCIA, R.G.; MENDES, A.A.; ANDRADE, C.; PAZ, I.C.L.A.; TAKAHASHI, S.E.; PELÍCIA, K.; KOMIYAMA, C.M.; QUINTEIRO, R.R. Avaliação do desempenho e de parâmetros gastrointestinais de frangos de corte alimentados com dietas formuladas com sorgo alto tanino e baixo tanino. Ciência e Agrotecnologia, v.29, n.6, p.1248-1257, 2005. 
Rev. Bras. Saúde Prod. Anim., Salvador, v.15, n.2, p.308-317 abr./jun., 2014 http://www.rbspa.ufba.br ISSN 15199940

GOBESSO, A.A.O.; D'AURIA, E.; PREZOTTO, L.D. Substituição de milho por sorgo triturado ou extrusado em dietas para equinos. Revista Brasileira de Zootecnia, v.37, n.11, p.2011-2016, 2008.

GOBESSO, A.A.O.; ETCHICHURY, M. Digestibilidade pré-cecal diurna e noturna em equinos fistulados alimentados com diferentes concentrados. Revista Brasileira de Saúde e Produção Animal [online], v.10, n.4, p.885-892, 2009.

GOBESSO, A.A.O.; ETCHICHURY, M.; TOSI, H. Resposta plasmática de glicose e insulina em eqüinos alimentados com diferentes fontes de amido. Brazilian Journal Veterinary, v.46, n.4, p.324-331, 2009.

GOLLCHER, A.M.R.; LIMA, J.A.F.; FIALHO, E.T.; RODRIGUES, P.B.; LIMA, R.R. Comparison between two methods for estimating the digestibility of starch and othr nutrients in high moisture sorhum grain silage in horses. Revista Brasileira de Zootecnia, v.39, n.6, p.1258, 2010.

IGARASI, M.S.; ARRIGON, M.B.; SOUZA, A.A.; SILVEIRA, A.C.; MARTINS, C.L.; OLIVEIRA, H.N. Desempenho de bovinos jovens alimentados com dietas contendo grão úmido de milho ou sorgo. Revista

Brasileira de Zootecnia, v.37, n.3, p. 513519, 2008a.

IGARASI, M.S.; ARRIGONI, M.B.; HADLICH, J.C.; SILVEIRA, A.C.; MARTINS, C.L.; OLIVEIRA, H.N. Características de carcaça e parâmetros de qualidade de carne de bovinos jovens alimentados com grãos úmidos de milho e sorgo. Revista Brasileira de Zootecnia, v.37, n.3, p.520-528, 2008 b.
ÍTAVO, C.C.B.F.; MORAIS, M.G.; ÍTAVO, L.C.V.; SOUZA, A.R.L.; DAVY, F.C.A.; ALBERTINI, T.Z.; COSTA, C.; LEMPP, B.; JOBIM, C.C. Padrão de fermentação e composição química de silagens de grãos úmidos de milho e sorgo submetidos ou não a inoculação microbiana. Revista Brasileira de Zootecnia, v.35, n.3, p. 655-664, 2006.

ÍTAVO, C.C.B.F.; MORAIS, M.G.; ITAVO, L.C.V.; SOUZA, A.R.D.L.; DAVY, F.C.A.; BILBERG, F.A.; ALVES, W.B.; SANTOS, M.V. Consumo e digestibilidade de nutrientes de dietas com silagens de grãos úmidos de milho ou sorgo, em ovinos. Arquivo Brasileiro de Medicina Veterinária e Zootecnia, v.61, n.2, p.452-459, 2009.

JULLIAND, V.; FOMBELE, A. de; VARLOUD, M. Starch digestion in horses: the impact of feed processing. Livestock Science, v.100, p.44-52, 2006.

NATIONAL RESEARCH COUNCIL NRC. Nutrients requirements of horses. 6.ed. Washington, 2007. 341p.

NOCEK, J.E. In situ and other methods to estimate ruminal protein and energy digestibility: a review. Journal of Dairy Science, v.71, n.8, p.2051-2069, 1988.

OLIVEIRA, K.; COSTA, C.; FAUSTINO, M.G. Valor nutritivo e estudo cinético do trato digestivo de dietas contendo grãos secos ou silagem de grãos úmidos de sorgo de baixo e alto tanino para equinos. Revista Brasileira de Zootecnia, v.36, n.6, p.1809-1819, 2007. 
Rev. Bras. Saúde Prod. Anim., Salvador, v.15, n.2, p.308-317 abr./jun., 2014 http://www.rbspa.ufba.br ISSN 15199940

OLIVEIRA, K.; COSTA, C;. BITTAR, C.M.M. Processamento da amostra das silagens de grãos úmidos de sorgo com baixo e alto teor de tanino na determinação da digestibilidade aparente em equinos. Boletim de Indústria Animal, v.69, n.1, p.33-40, 2012a.

OLIVEIRA, K.; BITTAR, C.M.M.; COSTA, C.; OLIVEIRA, V.A.B.; SA, J. Comparison of digestible markers from "in situ" and "in vivo" incubation to predict apparent digestibility in hay- and corn-fed horses. Acta Scientiarum Zootechny, v.34, n.1, p.27-33, 2012 b.

OLIVEIRA, K.; COSTA, C.; BITTAR, C.M.M.; OLIVEIRA, V.A.B.; SÁ, J.C. Nutritive value of high and low tanin content of sorghum high moisture silage for horses. Acta Scientiarum

Zootechny, v.35, n.1, p.93- 97, 2013.

PATRICIO, V.M.I.; FURLAN, A.C.; MOREIRA, I.; MARTINSE, M.; JOBIM, C.C.; COSTA, C. Avaliação nutricional da silagem dde grãos úmidos de sorgo de alto e baixo conteúdo de tanino para leitões. Revista Brasileira de Zootecnia, v.35, n.4, p.1406-1415, 2006.
ROONEY, L.W.; PFLUGFELDER, R.L. Factors affecting starch digestibility with special emphasis on sorghum and corn. Journal of Animal Science, v.63, n.3, p.1607-1623, 1986.

SANTOS, C.P.; FURTADO, C.E.; JOBIM, C.C. Avaliação da silagem de grãos úmidos de milho na alimentação de equinos em crescimento: valor nutricional e desempenho. Revista Brasileira de Zootecnia, v.31, n.3, p.1214-1222, 2003.

SCAPINELLO, C.; JOBIM, C.C.; FARIA, H.G. Silagem de grão úmido de milho na alimentação de coelhos em crescimento. Ciência Rural, v.41, n.3, p.507-512, 2011.

SILVA, D.J.; QUEIROZ, A.C. Análise de alimentos: métodos químicos e biológicos. 3ed.Viçosa, MG: UFV, 2006. $235 \mathrm{p}$.

STATISTICAL ANALYSIS SYSTEM. SAS user's: guide statistics. Cary: SAS Institute, 2000. 211p.

Data de recebimento: 24/09/2013

Data de aprovação: 22/05/2014 